\title{
Article \\ A New Experimental Investigation for Improving Bridge Management Systems and Road Operation Sustainability
}

\author{
Tullio Giuffrè ${ }^{D}$, Marinella Fossetti * and Alfio Francesco Siciliano \\ Faculty of Engineering and Architecture, “Kore” University of Enna, Cittadella Universitaria, 94100 Enna, Italy; \\ tullio.giuffre@unikore.it (T.G.); alfio.siciliano@unikore.it (A.F.S.) \\ * Correspondence: marinella.fossetti@unikore.it; Tel.: +39-0935-536442
}

Citation: Giuffrè, T.; Fossetti, M.; Siciliano, A.F. A New Experimental Investigation for Improving Bridge Management Systems and Road Operation Sustainability. Infrastructures 2021, 6, 31. https://doi.org/10.3390/ infrastructures6020031

Academic Editor: Valeria Vignali

Received: 27 December 2020

Accepted: 17 February 2021

Published: 20 February 2021

Publisher's Note: MDPI stays neutral with regard to jurisdictional claims in published maps and institutional affiliations.

Copyright: (c) 2021 by the authors. Licensee MDPI, Basel, Switzerland. This article is an open access article distributed under the terms and conditions of the Creative Commons Attribution (CC BY) license (https:// creativecommons.org/licenses/by/ $4.0 /)$.

\begin{abstract}
Generally, during maintenance operations on bridges and motorway viaducts, the circulation of vehicles is limited or suspended. This causes significant economic losses due to the increase in the costs of transport: delays, increased fuel consumption, higher emissions of pollutants into the atmosphere, increased risk of accidents, etc. However, few studies have analyzed the influence of bridge vibrations on the final mechanical properties of the cement mortar placing during ordinary bridge service. As such, interest is increasing in repair techniques that could achieve high structural performance without reducing road service levels. This paper provides the results obtained through an innovative laboratory trials campaign that evaluated the influence of vibrations on the mechanical properties of high-performance mortar used for repairing bridge decks. The results of 24 cubic and prismatic specimens showed the relationship between the traffic-induced vibrations and the mechanical characteristics of the studied mortar. The findings can be considered as the first methodologic step that is necessary to address further field studies, drawing a detailed link between the repair techniques and transportation user costs. Based on the obtained results, a synthetic bridge management system framework was developed that merges the road function into the structural issue with the goals of increasing the resilience of road networks and optimizing the maintenance resources budget.
\end{abstract}

Keywords: road rehabilitation; structural repairing of bridge decks; impact of vibrations on the mechanical features; maintenance program

\section{Introduction}

Road safety is required for the development of the economic and social activities of any country. The most vulnerable elements in a road network are the major road construction sites, particularly bridges and viaducts. The maintenance of this infrastructure requires in-depth investigation from the economic, engineering, and environmental [1] perspectives.

Generally, during maintenance operations on bridges and motorway viaducts, the circulation of vehicles is limited or suspended. The effects of traffic-induced vibrations on early-age mortar on the mechanical behavior of the repair material once it has hardened have not been studied. Currently, interest is increasing in asset management among transportation agencies around the world because infrastructure supports a nation's economic development, meets recreational and social needs, improves public health and safety, and promotes sustainability [2-4]. The rate of economic growth and development tends to slow when maintenance or retrofitting is required with the complete closure of a bridge [5].

During maintenance or retrofitting design activities on bridges, the use of highperformance mortar is required; as such, studies are needed, but lacking, that provide indications about the mechanical features of high-performance mortar placed without the complete removal from service of the bridge.

In an experimental analysis, the influence of vehicle-induced vibrations on the mechanical features of concrete was estimated by simulating the vibrations due to traffic with 
considerable limits, both on the application of vibrations input (generally only uniaxial vibrations generated by simple harmonic forcing) and on the direct measurement of the signals by actual bridges (vibration recordings of vehicle traffic are not easily reproducible).

An initial study was conducted by Hulshizer and Desai [6], who performed experimental vibration tests on concrete specimens arranged on uniaxial shaker tables to vibrate concrete rebar molds. Although a critical vibration threshold was never reached, in terms of peak particle velocity, the authors recommended that shock vibrations on fresh concrete should be conservatively limited to $102 \mathrm{~mm} / \mathrm{s}$ for concrete between 0 and $3 \mathrm{~h}$ old and $38 \mathrm{~mm} / \mathrm{s}$ for concrete between 3 and $11 \mathrm{~h}$ old.

Considering vibrations induced on early-age concrete via simple harmonic forcing, Harsh and Darwin [7] found that the framework did not minimize compressive strength in bridge deck repairs with low-slump concrete. However, a slump of more than $76 \mathrm{~mm}$ provided a reduction in the compressive strength of the concrete.

Dunham [8] found that different levels of uniaxial vibrations correspond to the common frequencies of vibratory soil compactors and the peak particle speed created by the compactors. The experimental results are similar to those reported in other studies.

Fernandes [9] observed the early-age behavior of high-strength concrete within an environment using a uniaxial vibrations framework. The data obtained underlined that vibrations reduce tensile strength; this must be considered for structures in which the tensile strength plays a key role in guaranteeing the system's durability.

Wei et al. [10] also studied the influence of forced vibration on the compressive strength of high-performance concrete by simulating vehicle-induced vibrations and bridge vibrations with a simple harmonic. Using different frequencies and amplitudes, they concluded that the amplitude of vibration has a prominent effect on the compressive strength of high-performance concrete specimens.

In Hong and Park's study [11], the vibrations used in the experimental test were obtained from the vibration recorded on existing bridge. The data obtained highlighted that vibrations induced by traffic do not alter the mechanical features of concrete if they act for less than six hours; for the other cases analyzed, the impact was not entirely negligible. However, Hong and Park [11] did not consider the high variability of the signals in the time and frequency domain that can result from the different geometric characteristics of the bridge decks.

More recent investigations showed that vehicle-induced vibrations tend to negatively affect cementitious composites in general. For example, they negatively affect both the tensile performance of early-age polyvinyl alcohol-engineering cementitious composites (PVA-ECCs) [12] and the flexural strength of newly placed PVA-ECCs [13].

Another problem regarding the research in this field is the recordings of vibrations induced by traffic, which are characterized by a wide frequency content that is hard to reproduce. For example, Gilbert [14] found that the difficulty of monitoring bridge decks is related to the cost and the complex setting of the acquisition system. For example, the use of accelerometers leads to complex signal-processing challenges, mainly due to transducer errors. The low-frequency noise and unknown initial conditions create many errors [15]. For this reason, studies are required on the vibrations of the infrastructure, focusing on signal-processing errors.

Within this context, the aim of this study was to provide experimental information, deduced using an innovative test procedure with an innovative test device, on the influence of vehicular traffic vibrations on the curing of cement mortars for structural retrofitting of bridge decks. In particular, the dynamic input was reproduced considering the randomness of the recorded signal and the variability in the geometric characteristics of bridges (different cross-section dimensions and number of spans). A 6DoF shaker was used to apply the real dynamic input.

The research goal was reached by linking the test procedure with field application. We provide the complementary analysis of the actual research findings on the new maintenance, repair, and rehabilitation (MR\&R) techniques used to improve a bridge's service level. This 
preliminary information is necessary for increasing the resilience of road networks and optimizing the budget of maintenance resources, as shown in Section 4.

As bridges and viaducts are critical to transportation infrastructure, their maintenance is essential to ensure their desired levels of serviceability and safety. Bridges serve as major road sections in mobility networks, providing solutions over waterways, areas of high altitude, and severe environmental features. When bridges are closed, costs increase as alternate routes are required. Then, bridge closures are unavoidable due to risk-induced repair and to planned MR\&R issues. When bridges have substandard vertical clearance or load capacity, certain heavy vehicles require detours since they cannot drive on or under those bridges. This inconvenience is commonly called user costs, as detailed in the next section.

\section{Feasibility of Inclusive Asset Management for Bridge Repair Operations}

In the literature, user cost models have been included in bridge management approaches to estimate safety, quantify substandard elements, and fix mobility advantages during the functional upgrading of bridges [16]. User costs typically include the costs sustained by users because of the level of service of the road in terms of deficiencies comparative to the desired road quality standards. User costs cover three key components: travel time cost, vehicle operating cost (VOC), and crash risk cost. VOCs include expenses directly incurred as a result of traffic operation: energy, liquids, restoration, maintenance, and vehicle devaluation.

In the literature, VOCs are related to heavy vehicle detours, as the longest route distance and travel time costs associated with the additional detour time [17]. Other studies have labeled the growth in adjustment features for several modules when estimating the VOCs $[18,19]$. Sinha and Labi [19] specified travel time as one of the main issues in the appraisal of alternative transportation assets. The authors further debated several issues regarding the value and sum of travel time. An advanced methodology was reported for combining the delay costs with calculated bridge user costs due to restrictions in bridge service level [20].

As stated above, trucks are rerouted to the shortest alternate route during bridge closures. Although this method may cover the effects of an out-of-service bridge, it does not consider the local or network impact. A detour strategy may have partial lane capacity, so the bridge being repaired may be able to handle a share of the rerouted traffic demand.

Researchers have focused on many different topics but mainly on predicting bridge conditions, selecting bridge maintenance by minimizing cost and maximizing benefits, integrating bridge data and geographical information, monitoring bridge condition in real time, and optimizing the allocation of maintenance resources. Although the prioritization of bridge rehabilitation has been identified as an important topic, studies in this area are limited. For example, considering a roadway section's constant width, the increase in vehicle flow increases the reciprocal interactions between vehicles, which decrease the outflow speed, so that the transition time of a road section increases. An intervention that could be applied is the lane extension, but it cannot always be implemented for many reasons, such as economic availability and geometric layout. It is useful to recognize these perspectives to find a solution that allows the increase of a road section's capacity without significant bridge interventions, minimizing both economic and environmental impacts. To ensure thorough consideration, it is necessary to exploit the characteristics of the existing bridge on the same route as much as possible, which is why it could be possible in the case of imminent traffic congestion to prevent emergency closure for a time frame until traffic congestion is over.

Usually, a bridge requires rehabilitation or replacement when it reaches a deficient condition. This excludes any vehicle collision with a bridge because, in those cases, bridge repairs are conducted under different regulations. Several researchers have studied the prediction of bridge condition ratings, especially deck and superstructure ratings. For example, Morcous [21] predicted bridge conditions by implementing a case-based 
reasoning (CBR) approach using inspection data of bridge decks in Québec, Canada. In another study, artificial neural network models were built with data from concrete bridge decks located in Hua Huang [22] to forecast deck ratings.

Some interest is focused on the uptake of digital services for transport, which will open further possibilities. Automation is only part of the vision; for transport systems to fully reap the benefits of automation, vehicles and infrastructure must be connected, increasing traffic management efficiency, improving the capacity of existing links, and increasing safety while reducing infrastructure maintenance costs by continuously monitoring the network, for instance.

Another crucial issue with bridge management is the limited budget assigned to infrastructure maintenance. Bridge preservation has to compete for resources with other transportation infrastructure elements, such as pavement, junctions, rail lines, etc. Thus, allocating these restricted funds poses a challenge for almost every transportation agency. It is crucial to optimize the budget in the best interest of the public.

Figure 1 shows how many countries (Italy, U.S., New Zealand, etc.) have assigned funds to road maintenance over the period between 2001 and 2017 [23]. The trend in each country's fund is linked to the special features of the road network and its main construction techniques and technologies. However, the technical literature does not provide specific data about bridge service level or maintenance management, with exceptions for some countries. The cost-benefit assessment is difficult due to maintenance policy, which considers advanced repairing techniques during traffic operations. In Italy, the recent Morandi Bridge tragedy [24] illustrated only a small part of the problem [25].

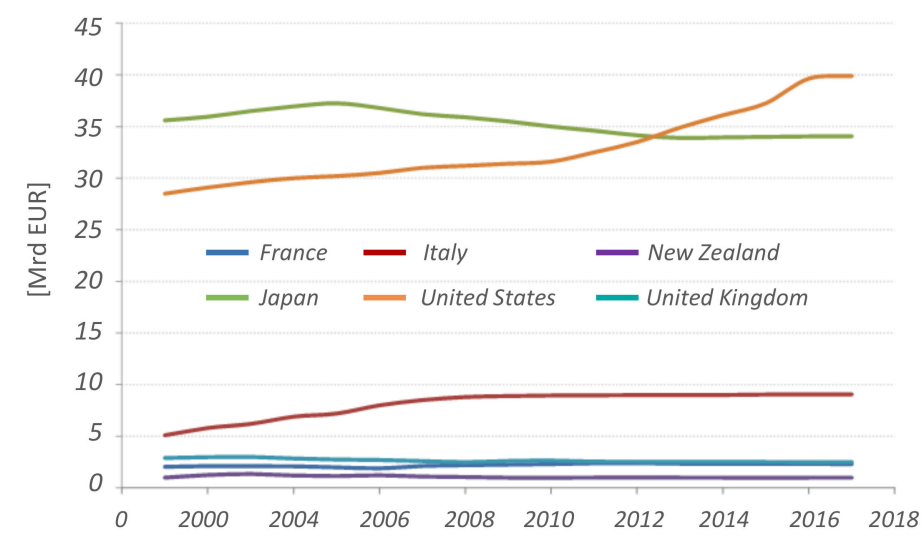

Figure 1. Road maintenance funds allocation in many countries.

Thus, researchers such as Zhang and Gao [26] have concentrated on defining better maintenance solutions for bridge decks to cover the predictable lifespan and reduce the expected life cycle cost of bridges. They suggested the Weibull distribution to shape the lifetime of bridge decks, and they compared three different maintenance scenarios. Likewise, Miyamoto et al. [27] constructed a bridge management system that offers a selection of maintenance approaches referring to bridge age (i.e., glass cloth + epoxy injection, etc.) by exploiting maintenance outcomes (quality) and minimalizing maintenance efforts. The authors used genetic algorithms to explain the optimization goal. A different perspective was provided by Elbehairy [28], who described a solution to choosing bridge deck repairs with a mixture of life cycle cost by applying genetic algorithms.

Despite the advantages of managed bridges, a different perspective has to be studied regarding cross-section and route changes. A dynamic lane has to be introduced in both directions, but only in the areas experiencing significant congestion. In such cases, it could be possible to manage the lanes of entire sections, reducing shoulder width and increasing buffer width close to the managed lane, so that drivers can drive in the dynamic lane that is perceived to be part of the entire road, which will help to keep their position in the lane axis at the highest speed. Using a hard shoulder as a dynamic lane enables continuous 
vehicle flow. There would be a higher collision risk with broken-down vehicles or other objects on the road. There must be permanent video surveillance of the bridge, especially for reverse lane use or other temporarily activated systems. A dynamic lane has to be managed to enhance traffic fluidity, ensuring services to increase and optimize roadway capacity, to temporarily close the bridge, and to ensure clearance. The value provided by bridge lane management can be evaluated by analyzing three main aspects: safety (incidents reduction), efficiency (reduction of travel time losses, more regular traffic flow), and environment noise and pollutant emission reductions. These parameters are described in Figure 2 and are called service radar [29].

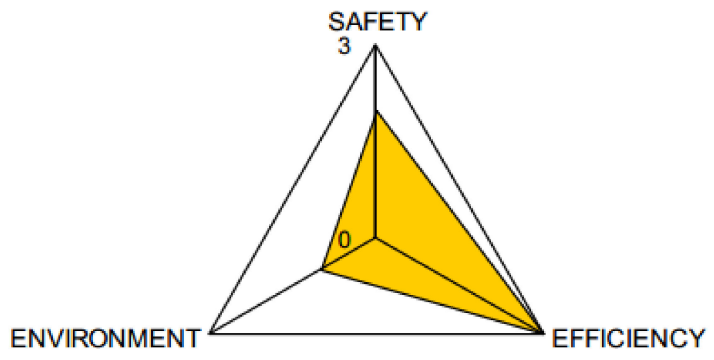

Figure 2. Effects of dynamic lane management service during bridge maintenance operations.

Several user cost studies have been conducted over the last two decades, essentially using two main approaches: most studies completed estimates based on the increased detour around the bridges, while few considered the impact on the transportation network. Using the detour approach, the benefits of functional improvement on bridges were assessed in terms of user cost savings [30]. Other important contributions are indicated in the literature [4,31-33].

In this field, we aimed to contribute to ordinary and/or extraordinary maintenance strategies that do not require the interruption of the road traffic, and to construct a synthetic bridge management system framework combining road function into the structural issue. Special considerations were needed to support the research approach within the application to existing road bridges, or to the traditional concrete (20th century) application, which is the most widespread in the European road network.

\section{Revisit of the Experimental Testing for Evaluating the Influence of Vibrations Induced by Traffic on Early-Age High-Performance Mortar}

To verify the influence of vibrations on the curing of cement mortars, an experimental test was conducted on 24 vibrated and control (non-vibrated) samples of high-performance mortar (MGF) with polyacrylonitrile synthetic fibers. This experimental research is a part of a larger experimental campaign [34].

MGF consists of a thixotropic pre-mixed mortar (one-component cementitious) with the following composition: aggregates, 30-40\% SR cement by UNI EN 197-1:2011 (sulfateresistant hydraulic binders), and $3-8 \%$ organic corrosion inhibitors and expansive additives. The fiber content is approximately $0.3 \%$ in terms of weight and their main mechanical characteristics are a Young's modulus of $72 \mathrm{GPa}$, tensile strength of $1700 \mathrm{MPa}$, length of $12 \mathrm{~mm}$, and diameter of $14 \mu \mathrm{m}$.

The use of MGF mortar is indicated when easy pumping is necessary for repairing deteriorated concrete at elevated positions, such as on bridge decks. For example, Brühwiler [35] conducted several studies on the use of high-performance fiber-reinforced mortar for the rehabilitation of road bridges. By efficiently combing the protection and resistance properties of this repairing material, it was found to significantly improve the structural performance in terms of the durability and life cycle costs of the rehabilitated concrete structure.

To assess the mechanical properties of MGF mortar, compression tests were carried out according to UNI EN 12390-3 [36] on 150-mm cubes, flexural tests according to UNI EN 
14651 [37] on $150 \times 150 \times 600$-mm prismatic specimens, hydrostatic weighing in according to EN 12390-7 [38] on 150-mm cubes, and ultrasonic tests according to UNI-EN 12504-4 [39] on 150-mm cubes.

The setting time was used to vibrate the samples. It was necessary to define the dynamic input that reproduces the effect due to vehicle traffic.

As mentioned in the Introduction, the majority of difficulties in similar studies were caused by the definition and application of the correct input for reproducing the vibrations induced by vehicular traffic, which is shown in the next section.

\subsection{The 6 DoF Shaker and Execution of Vibration Tests}

The vibration test was performed on a $6 \mathrm{DoF}$ shaker provided by the Team Corporation Ltd., model CUBE ${ }^{\mathrm{TM}}$ 2-DV-LS, available in the Experimental Dynamics Laboratory in the L.E.D.A. facility [40]. Six hydraulic actuators generate multi-axial vibration. In particular, with this device, it is possible to reproduce a random test with an assigned power spectral density (PSD). A control system allows operation in the frequency domain using a device for acquisition and control. The user interface is constituted by a PC. An acquisition system and some accelerometers were installed for data acquisition during the test.

An ad hoc design was applied for steel molds to be installed to the shaker. In particular, two kinds of steel molds were designed: the first system to be placed in the upper face of the CUBE ${ }^{\mathrm{TM}}$, and the second system to be fixed in the lateral faces of the shaker. The molds were designed using finite element analysis to assess the deflections to verify that the frequencies of the molds when full of mortar were far from those generated by the shaker during the vibration tests. Figure 3 shows the test set-up after casting the mortars.

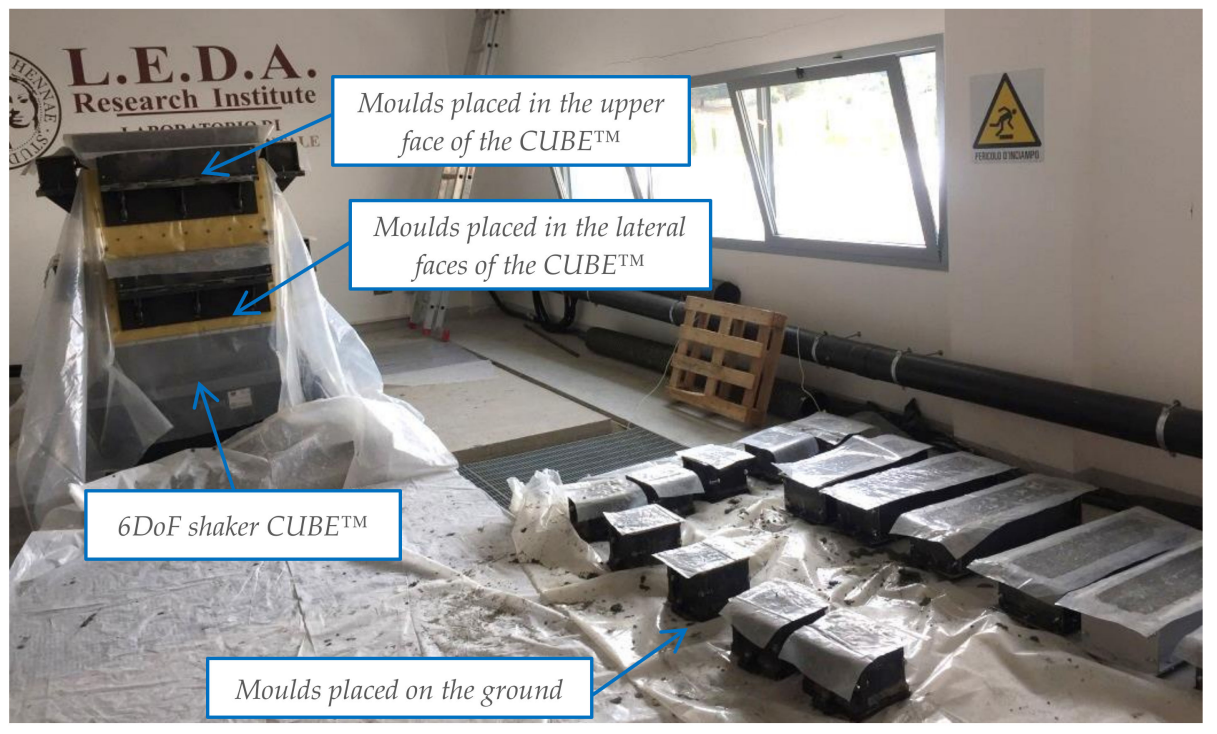

Figure 3. Experimental set-up for evaluating the influence of vehicle-induced vibrations.

The next step was developing a procedure to evaluate a PSD to assign as input to the CUBE ${ }^{\mathrm{TM}}$ using the recorded signals and for varying the geometric characteristics of different decks (Figure 4b). Numerous signals were assumed by the experimental recordings measured by Castellaro [41,42]. As an example, Figure 4a depicts a recorded signal on the vertical axis. The deck response is influenced by the speed of the moving loads, by their amplitude, and, above all, by its dynamic properties. To the limit, the single moving vertical load may be modeled as an impulsive concentrated force that moves at the speed of the vehicle [43]. 


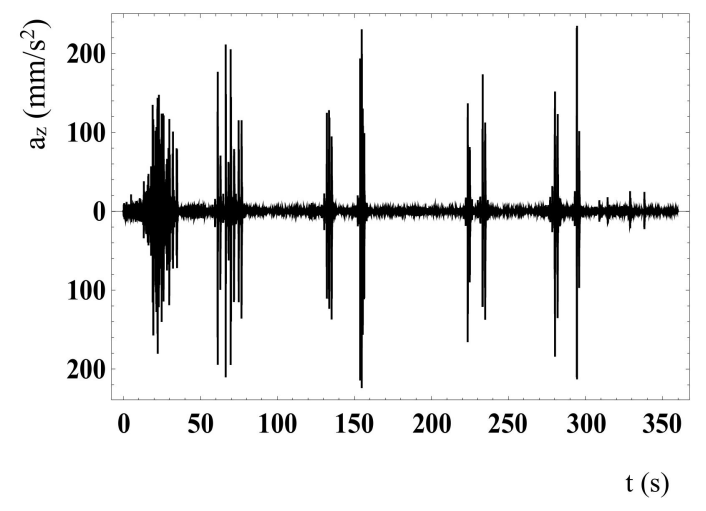

(a)

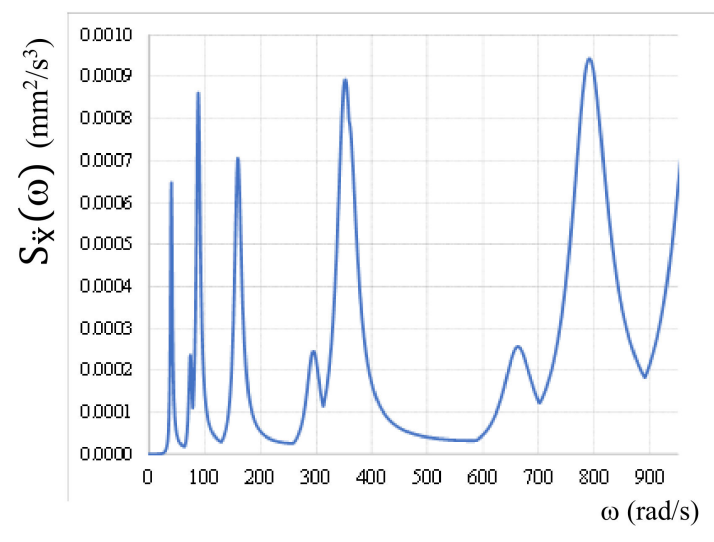

(b)

Figure 4. Example of (a) a recorded signal, considered for evaluating the power spectral density (PSD) function of the input; (b) PSD function of the input obtained.

The frequency content of an impulsive action is large; as the impulse is ideal, in the range of frequencies from zero to infinity, its energy content is constant. If forced by an action with constant energy at all frequencies (which is white noise if the highest frequency is infinite or pink noise if limited to a band), the structural system's response is defined by a frequency content that depends on its dynamic features: it vibrates at its own frequencies. As a consequence, we hypothesized that when the vehicles pass on the deck, it vibrates with its own frequency; for this reason, the vibration induced by the vehicles might be well-described by the square of the transfer function $\left(|\mathrm{H}(\omega)|^{2}\right)$ evaluated for the considered point along the deck, which we modeled as a simply supported beam. The transfer function relies only on the dynamic characteristics of the given structural system; when the system is forced by a stochastic action, the transfer function transforms the PSD of the input $\mathrm{SF}(\omega)$ in the PSD of the output $\mathrm{SX}(\omega)=\left.\mathrm{H}(\omega)\right|^{2} \mathrm{SF}(\omega)$. The PSD contains details on the quantity of energy of a fixed signal at every frequency value. Whenever the system is forced by white noise, $\mathrm{SF}(\omega)=\mathrm{S}_{0}$, and then $\mathrm{SX}(\omega)$ is proportional to $|\mathrm{H}(\omega)|^{2}$.

To create a dynamic and generic input, different cross-section dimensions and different numbers of spans of bridge decks were considered. For instance, Figure 5 depicts a particular cross-section of reinforced concrete highway bridges. The same figure shows the principal geometric properties of the considered decks. As the transfer function values vary on the beam, to obtain a generic dynamic input, three points were considered along the longitudinal axis of the decks of length $\mathrm{L}: \mathrm{L} / 2, \mathrm{~L} / 3$, and $\mathrm{L} / 4$. Therefore, the results in terms of the PSD of the acceleration calculated at these three points and for different decks were combined in only one envelope PSD function. This allowed us to consider the contribution of the first three modes of vibrations. The dynamic response yielded by the decks was characterized by a preliminary finite element analysis (see details in [34]).

The area under the PSD curve is the variance of the acceleration; its square root, the standard deviation, is related to the maximum acceleration produced via Monte Carlo simulations. Therefore, having defined the shape of the PSD starting from the dynamic characteristics of the considered decks, the ordinates were scaled to obtain the maximum amplitude of the acceleration of the same magnitude of the maximum vertical acceleration that occurs in reality.

We observed that, usually, the maximum vertical acceleration was in the range of $0.2-0.4 \mathrm{~m} / \mathrm{s}^{2}$; to cover some other possible uncertainties, the PSD was scaled to obtain a maximum peak corresponding to $2 \mathrm{~m} / \mathrm{s}^{2}$. More details of the procedure developed for the calculation of PSD are available in [34]. Figure $4 \mathrm{~b}$ depicts a PSD function evaluated through the developed procedure. 


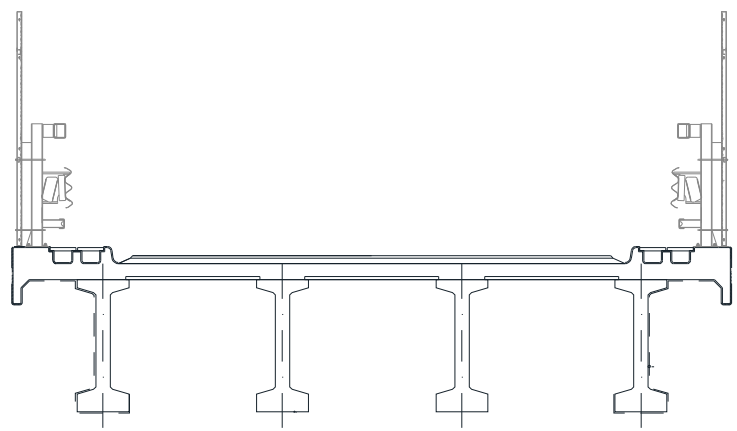

\begin{tabular}{|l|c|c|c|}
\hline Number of beams & 4 & 7 & 12 \\
\hline Span $[\mathrm{m}]$ & 29.00 & 32.00 & 19.00 \\
\hline Deck width $[\mathrm{m}]$ & 9.00 & 6.45 & 16.40 \\
\hline Slab height $[\mathrm{m}]$ & 0.20 & 0.21 & 0.22 \\
\hline Beam height $[\mathrm{m}]$ & 1.65 & 1.70 & 1.00 \\
\hline
\end{tabular}

Figure 5. Bridge decks. An example of typical cross-sections and the main geometric characteristics considered for evaluating the PSD function.

To obtain significant comparison parameters between the control and vibrated specimens, the control specimens were cast in molds on the floor of the room where the vibration test was conducted. To avoid sudden evaporation of the blend water, all the specimens were coated with a sheet of polyethylene (Figure 3). The simulated vibrations were applied to the specimens for a duration equal to the setting time. In particular, by means of Vicat's apparatus (UNI EN 196-3:2005, [44]), the time of the initial set and the final set was evaluated in the eight hours after the preparation of the specimens. After $24 \mathrm{~h}$, using water at a temperature of $20^{\circ} \mathrm{C}$, the specimens were demolded and cured.

\subsection{Mechanical Characterization of Control and Vibrated Specimens}

Before the destructive tests, the cube specimens were subjected to non-destructive testing. In particular, hydrostatic weighing and ultrasonic tests were conducted to evaluate the mass density and the modulus of elasticity $\left(\mathrm{E}_{\mathrm{c}}\right)$, respectively. The tests were conducted for three equivalent specimens of fixed ages.

Hydrostatic weighing was performed according to EN 12390-7 [38]. The total average mass density for vibrated and control samples was 2171 and $2182 \mathrm{~kg} / \mathrm{m}^{3}$, respectively. The experimental results highlighted that vibrations did not induce significant variations (around 5\%) in the volume and mass density of the samples.

An ultrasonic test was performed according to UNI-EN 12504-4 [39]. Figure 6 compares the modulus of elasticity of the two kinds of sample: non-vibrated (control) and vibrated.

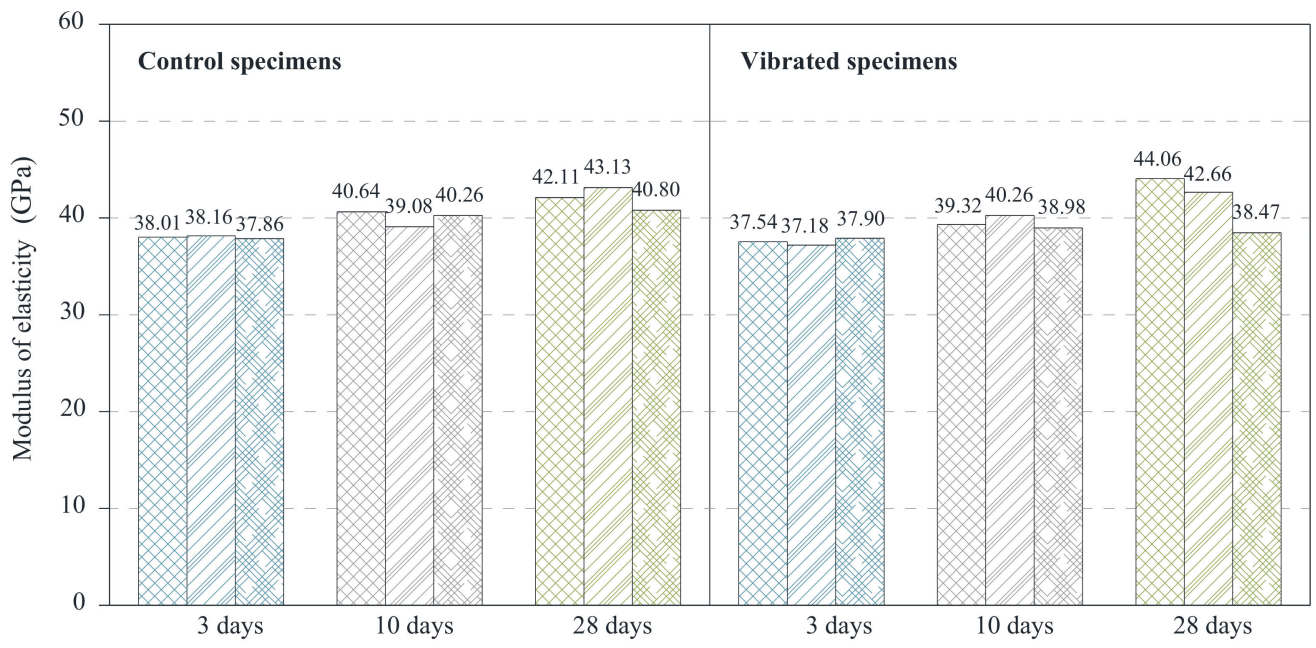

Figure 6. Modulus of elasticity $\left(\mathrm{E}_{\mathrm{c}}\right)$ of non-vibrated and vibrated specimens of different ages..

We determined that the impact of the induced vibrations on the $\mathrm{E}_{\mathrm{c}}$ for control specimens with respect to vibrated ones was usually somewhat greater, mainly in the early 
age ( $1.25 \%$ after the first 3 days), and decreased as age increased ( $0.68 \%$ at 28 days). The average $E_{c}$ at 28 days was $41,729 \mathrm{MPa}$ for vibrated samples and 42,015 $\mathrm{MPa}$ for nonvibrated samples.

In general, we observed that the volume, the mass density, and the modulus of elasticity $E_{C}$ were not greatly altered by induced vibrations.

At 3,10 , and $28 \pm 1$ days, compression tests were conducted according to UNI EN 12390-3 [36] to evaluate the compressive strength $R_{c}$. The tests were conducted for at least three specimens with analogous features. The ratio of the axial load and the cross-section area of the samples gives the compressive strength. Figure 7 compares the compressive strength of the non-vibrated and vibrated specimens.

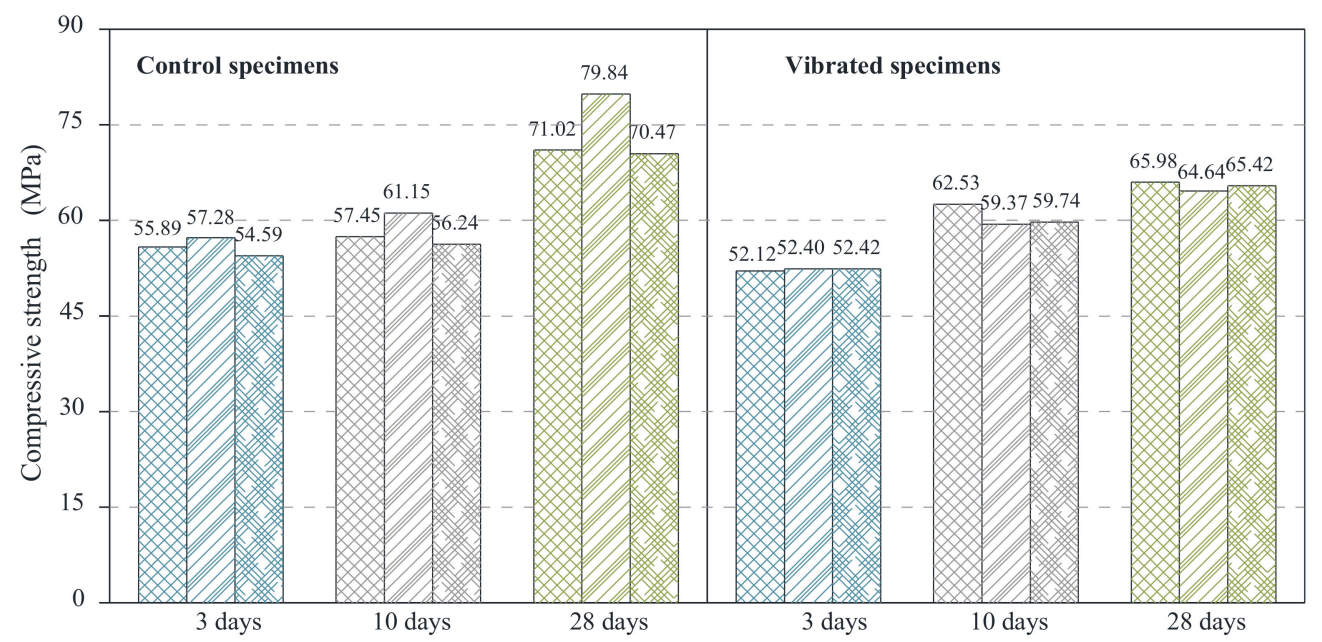

Figure 7. Compressive strength $\mathrm{R}_{\mathrm{c}}$ of non-vibrated and vibrated specimens of different ages.

The value assumed for the compressive strength $R_{c}$ was calculated as the mean value of analogous specimens subjected to compression tests. The compressive strengths calculated for non-vibrated and vibrated samples were: 55.92 and $52.31 \mathrm{MPa}$ at 3 days of age, 58.28 and $60.55 \mathrm{MPa}$ at 10 days of age, and 73.78 and $65.35 \mathrm{MPa}$ at 28 days of age, respectively.

The impact of the induced vibrations was noticeable since the $R_{c}$ decreased as the age of the mortars increased. In particular, at 28 days of age, we noted a $11.43 \%$ reduction in the non-vibrated samples compared to vibrated ones. This experimental result agrees with Hong and Park [11], who evaluated vibrations input from a vibration test of an actual bridge, as in the present study. However, this finding disagrees with previous studies in which the vibration characteristics were not derived from actual bridges [7-9].

In particular, the comparison of our result (reduction of $11.43 \%$ after $8 \mathrm{~h}$ of vibrations) and that obtained by Hong and Park [11] (reduction of 10.77\% after $6 \mathrm{~h}$ of vibrations) validates the conclusions of our experimental study.

The tensile flexural behavior was evaluated using three-point bending tests, which were conducted at $28 \pm 1$ days according to UNI EN 14651 [37]. The samples with the geometric characteristics depicted in Figure 8a were used to evaluate the load-crack mouth opening displacement (load-CMOD) through the application of a center-point load. Figure $8 \mathrm{~b}$ shows the results obtained as a mean of two specimens with analogous characteristics. The CMOD was measured using a 0.01-accuracy LVDT transducer. 


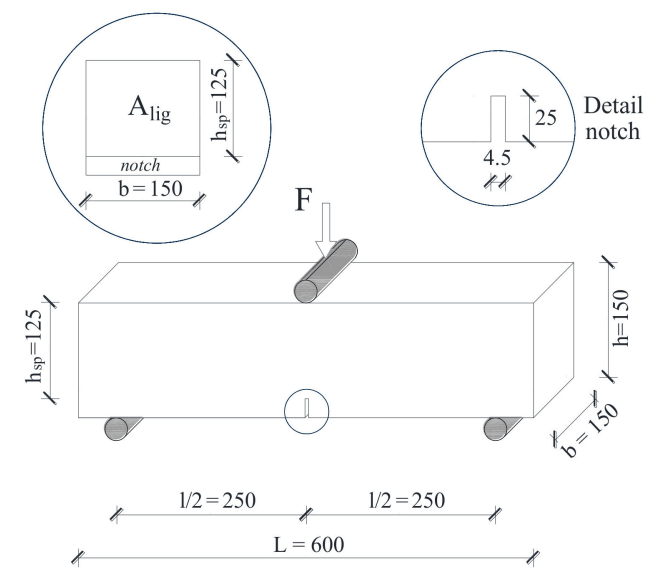

(a)

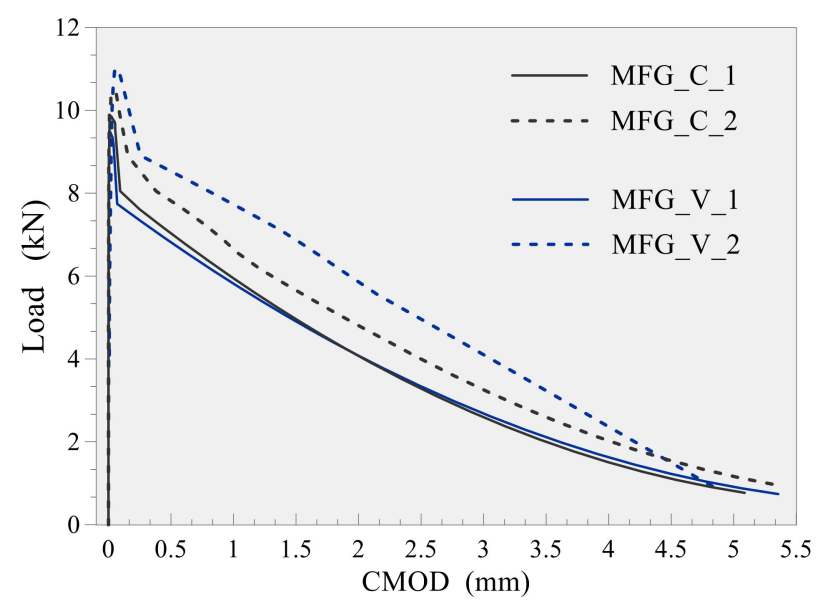

(b)

Figure 8. (a) Characteristics of the experimental set-up of the three-point bending loading; (b) load-CMOD curves.

The tensile flexural behavior was calculated as tensile flexural strengths $\mathrm{f}_{\mathrm{ct}, \mathrm{L}}$ and residual tensile flexural strength $\mathrm{f}_{\mathrm{R}, \mathrm{j}}$ (with $\left.\mathrm{j}=1,2,3,4\right)$. In particular, we assessed $\mathrm{f}_{\mathrm{ct}, \mathrm{L}}$ as the maximum load value in the CMOD interval of $0 \div 0.05 \mathrm{~mm}$ and $\mathrm{f}_{\mathrm{R}, \mathrm{j}}$ as the load corresponding to $\mathrm{CMOD}_{\mathrm{j}}\left(\mathrm{CMOD}_{1}=0.5 \mathrm{~mm} ; \mathrm{CMOD}_{2}=1.5 \mathrm{~mm} ; \mathrm{CMOD}_{3}=2.5 \mathrm{~mm}\right.$; $\left.\mathrm{CMOD}_{4}=3.5 \mathrm{~mm}\right)$.

The fracture energy $\mathrm{G}_{\mathrm{F}}$ and the fracture toughness $\mathrm{K}_{\mathrm{IC}}$ were evaluated as representative mechanical parameters of the post-cracking behavior of the mortar analyzed. $\mathrm{K}_{\mathrm{IC}}$ and $\mathrm{G}_{\mathrm{F}}$ were considered because in bridges, repair materials that are able to absorb exceptional loads (such as impact loads) must be used.

The fracture energy $\mathrm{G}_{\mathrm{F}}$ was calculated following RILEM 1985 TC 50-FMC [45]. Although the method in RILEM 1985 TC 50-FMC [45] is proposed to evaluate the parameter $\mathrm{G}_{\mathrm{F}}$ for ordinary concrete, it was recently followed by numerous researchers for fiberreinforced high-performance mortar [46]. Fracture toughness $\mathrm{K}_{\mathrm{IC}}$ was evaluated following Karihaloo and Nallathambi [47]. The details of the calculations of $\mathrm{G}_{\mathrm{F}}$ and $\mathrm{K}_{\mathrm{IC}}$ are provided in [34]; Table 1 presents the tensile characteristics estimated from our experimental study.

Table 1. Key results of tensile behavior.

\begin{tabular}{|c|c|c|c|c|c|c|c|}
\hline \multirow{3}{*}{ Setting Technique } & \multirow{2}{*}{$\begin{array}{c}\begin{array}{c}\text { Tensile Flexural } \\
\text { Strength }\end{array} \\
\mathbf{f}_{\mathrm{ct}, \mathrm{L}}\end{array}$} & \multicolumn{4}{|c|}{ Residual Tensile Flexural Strength } & \multirow{2}{*}{$\begin{array}{c}\text { Fracture Energy } \\
\mathrm{G}_{\mathrm{F}}\end{array}$} & \multirow{2}{*}{$\begin{array}{c}\text { Fracture Toughness } \\
\mathrm{K}_{\mathrm{IC}}\end{array}$} \\
\hline & & $\mathbf{f}_{\mathbf{R}, 1}$ & $\mathbf{f}_{\mathrm{R}, 2}$ & $f_{R, 3}$ & $f_{R, 4}$ & & \\
\hline & (MPa) & (MPa) & (MPa) & (MPa) & (MPa) & $\mathrm{N} / \mathrm{mm}$ & $\mathrm{MPa} \mathrm{mm}^{1 / 2}$ \\
\hline without & 3.15 & 2.23 & 1.62 & 1.06 & 0.61 & 0.90 & 20.84 \\
\hline vibrations (C) & 3.34 & 2.51 & 1.80 & 1.22 & 0.84 & 1.20 & 22.88 \\
\hline with & 3.03 & 2.15 & 1.56 & 1.02 & 0.68 & 0.91 & 18.95 \\
\hline vibrations (V) & 3.50 & 2.73 & 2.23 & 1.53 & 1.04 & 1.07 & 26.34 \\
\hline
\end{tabular}

The results in Table 1 highlight that the induced vibrations did not negatively influence the tensile characteristic of the high-performance mortar used as a repair material for bridge decks.

As an example, considering the mean value of analogous specimens, the residual tensile flexural strengths of vibrated specimens with respect to non-vibrated ones were higher in the post-peak branch by $2.86 \%, 10.46 \%, 11.72 \%$, and $18.28 \%$ for $f_{R, 1}, f_{R, 2}, f_{R, 3}$, and $\mathrm{f}_{\mathrm{R}, 4}$, respectively. Figure 9 highlights these conclusions. 


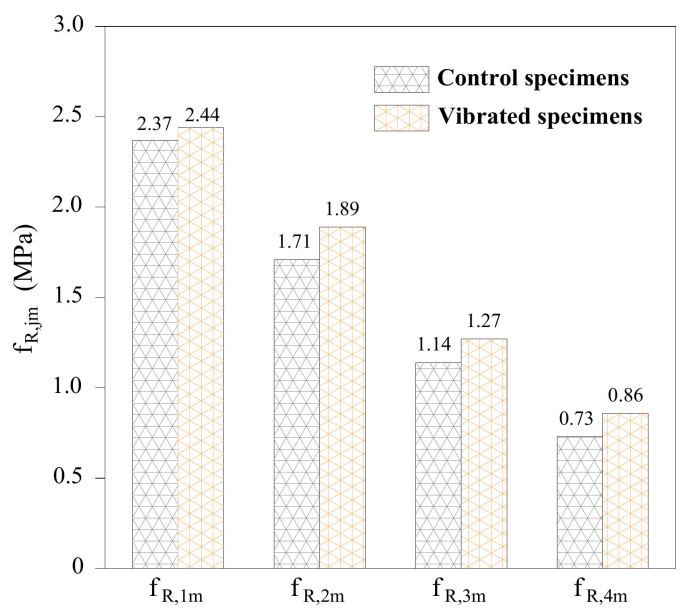

Figure 9. Residual flexural tensile strengths of control and vibrated specimens.

In conclusion, although new experimental analyses are necessary to generalize these data, we can assume that the vibrations induced in the fibers contained in MGF result in an increase in the tensile flexural behavior of the considered mortar.

\section{The Importance of a Bridge Management System}

For an efficient structural treatment when the functional features of a bridge or viaduct need to be rehabilitated, the whole process should be determined using a bridge management system. The rehabilitation activities can be either recommended or mandatory and should be conducted according to a technical policy controlled by certain authorities.

Figure 10 illustrates the bridge management system based on several consecutive steps, which, in this study, was developed as an extension of previous work [27] merging road function into the structural issue. In Step 1, the action involves surveying the whole framework of a bridge. In Step 2, decision-makers arrange for all engineering activities (structural, transportation, etc.) needed for the treatment design and rehabilitation process. Step 3 is the period of works, depending on the specific repair approach (full rehabilitation, partial rehabilitation, or replacement). Finally, Step 4 considers the long-term bridge services and when it should be monitored using the best maintenance strategy.

\begin{tabular}{|c|c|c|c|c|c|c|c|c|c|c|c|c|c|c|}
\hline & \multicolumn{14}{|c|}{ Bridge Management System step } \\
\hline & \multicolumn{3}{|c|}{1} & \multicolumn{4}{|c|}{2} & \multicolumn{3}{|c|}{3} & \multicolumn{4}{|c|}{4} \\
\hline Action & $\begin{array}{c}\text { Structural } \\
\text { Data }\end{array}$ & Traffic Data & $\begin{array}{c}\text { Environment } \\
\text { Data }\end{array}$ & $\begin{array}{c}\text { Structural } \\
\text { Treatment } \\
\text { program }\end{array}$ & $\begin{array}{l}\text { Route } \\
\text { Analysis }\end{array}$ & $\begin{array}{c}\text { Functional } \\
\text { Evaluation \& } \\
\text { Risk Indexing }\end{array}$ & $\begin{array}{c}\text { Rehabilitation } \\
\text { Cost } \\
\text { Evaluation }\end{array}$ & \begin{tabular}{|c|} 
Full \\
Rehabilitation
\end{tabular} & $\begin{array}{c}\text { Partial } \\
\text { Rehabilitation }\end{array}$ & Replacement & $\begin{array}{c}\text { Site } \\
\text { Inspection }\end{array}$ & $\begin{array}{c}\text { Structural } \\
\text { Test }\end{array}$ & $\begin{array}{c}\text { Structural } \\
\text { Health } \\
\text { Monitoring }\end{array}$ & $\begin{array}{c}\text { Maintenance } \\
\text { Planning }\end{array}$ \\
\hline & \multicolumn{3}{|c|}{ 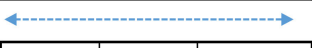 } & \multicolumn{4}{|c|}{ 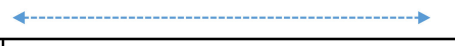 } & \multicolumn{7}{|c|}{ 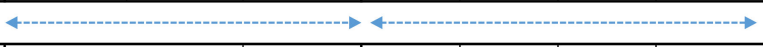 } \\
\hline Function & $\begin{array}{c}\text { Big Data \& } \\
\text { Mapping }\end{array}$ & \begin{tabular}{|l|} 
Structural \\
Evaluation
\end{tabular} & $\begin{array}{l}\text { Functional } \\
\text { Evaluation }\end{array}$ & \multicolumn{4}{|c|}{ Design \& Budgeting } & \multicolumn{2}{|c|}{$\begin{array}{c}\text { Route clearance \& Traffic } \\
\text { Alteration }\end{array}$} & $\begin{array}{l}\text { Structural } \\
\text { Repair }\end{array}$ & $\begin{array}{l}\text { Damages } \\
\text { Modeling }\end{array}$ & $\begin{array}{c}\text { Hazard } \\
\text { Prevention }\end{array}$ & \begin{tabular}{|} 
Regular \\
Road \\
Operation
\end{tabular} & $\begin{array}{c}\text { Cost } \\
\text { Optmization }\end{array}$ \\
\hline & \multicolumn{7}{|c|}{ 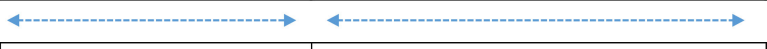 } & \multicolumn{7}{|c|}{ 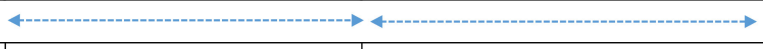 } \\
\hline Step & \multicolumn{3}{|c|}{ Survey } & \multicolumn{4}{|c|}{ Engineering } & \multicolumn{3}{|c|}{ Maintenance Work } & \multicolumn{4}{|c|}{ Monitoring \& Mitigation } \\
\hline
\end{tabular}

Figure 10. Synthetic timeline of the bridge management system.

The obtained experimental results can significantly affect traffic route alterations and therefore the overall bridge management system, as shown in Figure 10. For instance, if the material used to repair a bridge deck is mainly under tension, the rehabilitation technique can be implemented without vehicular traffic interruptions. In other cases, e.g., when 
compression is dominant, the closure of the bridge can be programmed on the basis of the results presented in Section 3.2.

It is relevant to discuss how the bridge repair approach depicted leads to traffic route alteration. Several approaches were tested to determine the most suitable routing solution (for example, mobile ad hoc network, destination sequenced distance vector) [48]. Route planning is expected to avoid any issue that may increase traveling time along the route during restoration period.

The analysis of the route alternatives scenario is aimed at estimating the impact in socioeconomic terms of the functionality of the bridge, understood as an element of the transport network capable of ensuring connection and accessibility functions between the areas of the territory, its activities and its production, consumption, logistics, and distribution sites. Then, studies could be considered that were part of the original project documentation (analysis of demand and results of traffic assignments, socioeconomic impact assessments, B-C and/or multi-criteria analysis, etc.) and/or data available from territorial government bodies or other subjects verifying that the assumptions on which they are based remain valid (the territorial and settlement transformations of activities are negligible, the networks have not undergone substantial changes, etc.). The studies carried out in the field are of particular importance within transport planning activities on a regional and local scale (regional transport plans, basin plans, local transport plans, mobility plans, feasibility studies, etc.). Comparisons aimed at verifying the relevance and usability of the studies that can be acquired must be accompanied by any temporary flow counting sessions that can validate the studies or highlight their need for updating. Both passenger demand and freight demand must be considered.

In any case, it is necessary to clarify the impact of the "repairing bridge" in terms of absorption of the allocation rate relating to different origin-destination matrixes and contributions to the active and passive accessibility of the localization areas of the activities commercial and productive residential areas.

Currently, the goal of resilient infrastructure is to reduce: (1) route cost, (2) route distance, (3) travel time, and (4) user dissatisfaction [49]. The findings could lead to the definition of new policies for improving the resilience of road facilities using the bridge management system in Figure 10.

Hard shoulder running, for example, is a technique used to improve service quality, mainly on highways and freeways where there are bridge management issues; this technique is mainly associated with traffic management. However, its implementation has several impacts that have to be evaluated as safety or bridge load capability change due to the traffic configuration. The pavement performance of an existing bridge is negatively affected by increases in load. For instance, considering a two-lane case where load is divided roughly on each side, an additional lane would change the distribution, creating a condition where loads would be roughly distributed into three parts; if pavement layers were not designed for such configurations, rapid road pavement degradation would require maintenance interventions. For these reasons, analyses must evaluate the bearing capacity of the existing pavement. Design criteria for pavement vary and mainly consider two parameters: bridge design load and pavement layer thickness. The most used criteria are equivalent single-axle load (ESAL) for load evaluation and American Association of State Highway and Transportation Officials (AASHTO) for design and construction [50].

Contrary to the previous case, if a critical situation emerges from the evaluation of the bridge static safety level according to current standards, it is necessary in a short time to design structural interventions aimed at achieving acceptable safety levels. However, it is possible, in order to ensure a minimum passage on the bridge, in the period necessary for the design and construction interventions, to take measures to limit use or limit loads. In the case of limitation of use, it is possible to allow the passage of vehicles on a single lane instead of two, or similar measures verifying the complex flexion-torsional behavior of the bridge and of the lateral parts, which is the most favorable position in the security comparisons for the passage. 
The proposed methodology should allow the resolution of issues such as accidents and crowding during restoration operations.

The implementation of a new bridge management system is also crucial as experience from past case studies indicated a different factor: the deficiency in the road capacity to lever the circulation during a large-scale bridge rehabilitation program.

As shown in Figure 11, the solution reached through the application of the bridge management can be simplified into hierarchically organized sub-processes. The top level of this hierarchical process can be divided into three aspects: understanding the stock, making decisions, and implementing interventions. The latter can be further organized into sub-levels with no fixed structure. Generally, it includes replacing the damaged structures, managing supply chains, and maintenance activities. Hence, in a model of bridge management, as defined in Figure 11, the rehabilitation activities mentioned above are framed on the third level as maintaining and improving structures.

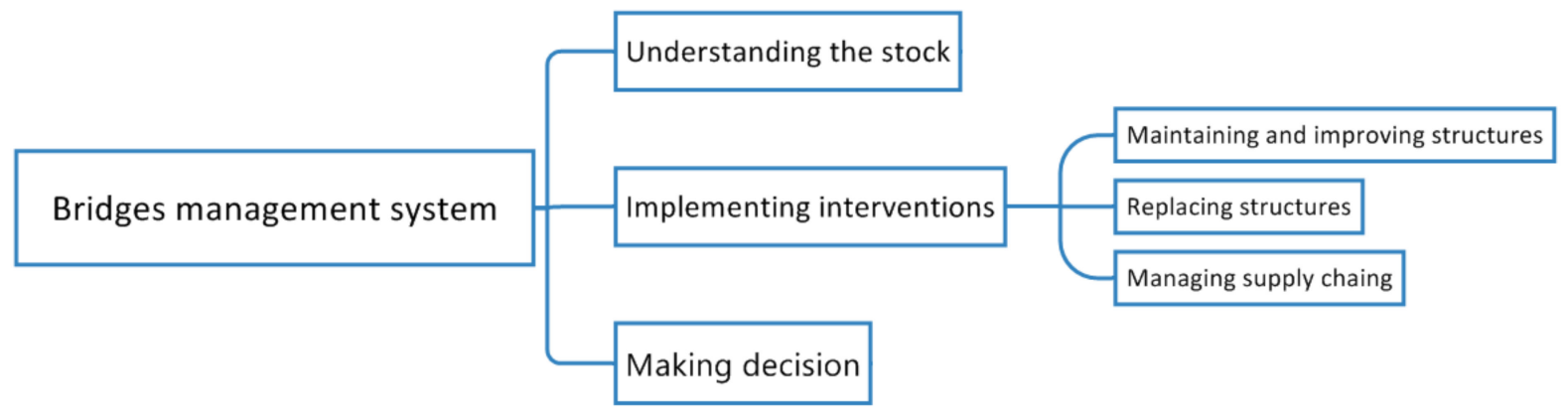

Figure 11. Solution paradigm identified by the bridge management system [51].

The traditional approach, which guaranteed the shortest travel time alone, does not ensure the effectiveness of the optional journey, so specific engineering action is required to evaluate the real cost of transportation. This operation almost needs the availability of self-tailored digital architecture and software components. Typically, Bridge Management System (BMS) software consists of at least the following sections:

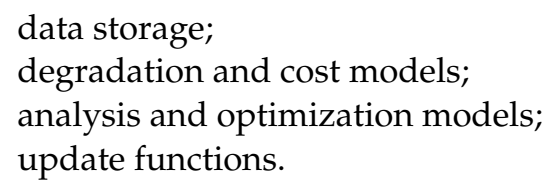

In the current context, the communication and interchange functions (interoperability) with other software are also important, of the same type and at a higher territorial level, or for the execution of specialized functions, such as the BIM modeling, analysis, and structural design of interventions. From a functional point of view, it is recommended that BMSs have at least the following requirements:

Inventory management, with links to project and testing data, where available, or to first inspection data;

GIS interface;

Friendly user interface;

Differentiated management of access;

Management of inspections and synthesis of the results of instrumental monitoring, with interface to the software management of monitoring systems;

Management of risk classes;

Management of the results of investigations and tests;

Management of alarm thresholds;

Any transit limitations and time limits for extraordinary maintenance/retrofitting;

Interface with BIM models and calculation models;

Statistical processing and creation of standard periodic reports. 
The previous methodology is currently being refined in several road authorities around the world and research on new repair techniques is considered a necessity in order to ensure the sustainability of future transportation.

\section{Conclusions}

Typically, bridge maintenance or retrofitting design activities require the use of highperformance mortar. Therefore, studies are required that provide indications about the mechanical features of the high-performance mortar that is placed without taking the bridge completely out of service. Only a few recent studies researched this kind of application and this situation, which was the motivation for this study.

In particular, this paper presented the results derived from new test equipment (the innovative $6 \mathrm{DoF}$ shaker, which is able to reproduce the real dynamic behavior of the analyzed repair material), which was used to evaluate the impact of induced vibrations derived from vehicle traffic on the mechanical characteristics of the high-performance mortar used for bridge repairs. The dynamic input was evaluated considering the randomness of recordings of vibrations produced by vehicle traffic and the evolution of the geometric characteristics of real bridges. The impact of induced vibrations was estimated by comparing the experimental behavior of 24 cubic and prismatic vibrated and non-vibrated samples in terms of compression and tensile flexural behavior. A fiber-reinforced mortar was considered with short polyacrylonitrile synthetic fibers, which is indicated for bridge repair when high fluidity is required for easy pumping.

Considering the impact of the induced vibrations, the obtained results highlighted some key factors in the scheduling of maintenance activities of bridge decks; we developed a synthetic bridge management system framework that considers the possibility of preserving the road circulation during the bridge repair activities, which would lead to significant economic savings.

These results need to be considered as an important step toward further field studies, which could provide a relevant contribution to ordinary and/or extraordinary maintenance strategies of bridges, as several bridges have now been exploited for their entire life cycle in service and their maintenance is urgently needed around the world; careful maintenance can increase the life cycle of the structures by up to $70 \%$. A lower overall cost $(40 \%$ reduction) is expected when maintenance is adopted with respect to a shorter structure life because demolition and reconstruction is more expensive, in terms of social costs as well.

Author Contributions: T.G. provided the framework for the research program and the methodological approach for bridge management system. A.F.S. and M.F. performed the experimental testing and developed the analysis of obtained data. Moreover, M.F. provided oversight and high level editorial review of the paper. All authors have read and agreed to the published version of the manuscript.

Funding: This research received no external funding.

Informed Consent Statement: Informed consent was obtained from all subjects involved in the study.

Data Availability Statement: The data presented in this study are available on request from the corresponding author.

Acknowledgments: The authors thank the personnel of Experimental Dynamics Laboratory in the L.E.D.A. facility of Enna for their contributions.

Conflicts of Interest: The authors declare no conflict of interest.

\section{References}

1. Giunta, M. Assessment of the environmental impact of road construction: Modelling and prediction of fine particulate matter emissions. Build. Environ. 2020, 176, 106865. [CrossRef]

2. Robak, A.; Monkman, D.; Gilberston, T.; Bush, S.; O'Connor, B.; Blakemore, R.; Garlik, S.; Hughes, J.; Gordon, M.; Sharman, B.; et al. IIMM International Infrastructure Management Manual 2015; Institute of Public Works Engineering Australasia (IPWEA): Auckland, New Zealand, 2015. 
3. Shau, H.J.; Liu, T.Y.; Chen, P.H.; Chou, N.N.S. Sustainability Practices for the Suhua Highway Improvement Project in Taiwan. Int. J. Civ. Eng. 2019, 17, 1631-1641. [CrossRef]

4. Giunta, M. Sustainability and resilience in the rehabilitation of road infrastructures after an extreme event: An integrated approach. Balt. J. Road Bridge Eng. 2017, 12, 154-160. [CrossRef]

5. Munasinghe, M.; Clarke, C.L.; World, B. Disaster Prevention for Sustainable Development: Economic and Policy Issues: A Report from the Yokohama World Conference on Natural Disaster Reduct; World Bank: Washington, DC, USA, 1995.

6. Hulshizer, A.J.; Desai, A.J. Shock Vibration Effects on Freshly Placed Concrete. J. Construct. Eng. Manag. 1984, 110, 266-285. [CrossRef]

7. Harsh, S.; Darwin, D. Traffic Induced Vibrations and Bridge Deck Repairs. Concr. Int. Des. Constr. 1986, 8, 36-42.

8. Dunham, M.R.; Rush, A.S.; Hanson, J.H. Effects of Induced Vibrations on Early Age Concrete. J. Perform. Constr. Facil. 2007, 21, 179-184. [CrossRef]

9. Fernandes, J.F.; Bittencourt, T.N.; Helene, P. Concrete subjected to vibrations in early-ages. Ibracon Struct. Mater. J. 2011, 4, 592-609. [CrossRef]

10. Wei, W.; Shuo, L.; Qizhi, W.; Wei, Y.; Mingzhang, C.; Xiaotian, H.; Shuai, M.; Xuanyu, L. The Impact of Traffic-Induced Bridge Vibration on Rapid Repairing High-Performance Concrete for Bridge Deck Pavement Repairs. Adv. Mater. Sci. Eng. 2014, 2014, 9.

11. Hong, S.; Park, S. Effect of vehicle-induced vibrations on early-age concrete during bridge widening. Constr. Build. Mater. 2015, 77, 179-186. [CrossRef]

12. Zhang, X.; Liu, S.; Yan, C.; Wang, X.; Wang, H. Effects of Vehicle-Induced Vibrations on the Tensile Performance of Early-Age PVA-ECC. Materials 2019, 12, 2652. [CrossRef] [PubMed]

13. Zhang, X.; Liu, S.; Yan, C.; Wang, X.; Wang, H. Effects of Traffic Vibrations on the Flexural Properties of Newly Placed PVA-ECC. Bridge Repairs Mater. 2019, 12, 3337.

14. Gilbert, H.B.; Celik, O.; O'Malley, M.K. Long-Term Double Integration of Acceleration for Position Sensing and Frequency Domain System Identification. In Proceedings of the International Conference on Advanced Intelligent Mechatronics, Montreal, QC, Canada, 6-9 July 2010.

15. Arraigada, M.; Partl, M. Calculation of Displacements of Measured Accelerations, Analysis of Two Accelerometers and Application in Road Engineering. In Proceedings of the 6th Swiss Transport Research Conference, Ascona, Switzerland, 15-17 March 2006.

16. Sobanjo, J.O.; Thompson, P.D. Enhancement of the FDOT's Project Level and Network Level Bridge Management Analysis Tools, Technical Report BDK83, 977-01; Florida State University: Tallahassee, FA, USA, 2011.

17. Thompson, P.D.; Najafi, F.T.; Soares, R.; Choung, H.J. Development of user cost data for Florida's bridge management system. In USA-Report; University of Florida: Tallahassee, FA, USA, 1999; pp. 1-49.

18. Barnes, G.; Langworthy, P. Per-mile costs of Operating Automobiles and Trucks. J. Trans. Res. 2004, 1864, 71-77. [CrossRef]

19. Sinha, K.; Labi, S. Transportation Decision Making; Wiley: New York, NY, USA, 2007.

20. Bai, Q.; Labi, S.; Sinha, K.C.; Thompson, P.D. Bridge user cost estimation-a synthesis of existing methods and addressing the issues of multiple counting, workzones and traffic capacity limitation. Struct. Infrastruct. Eng. 2013, 9, 849-859. [CrossRef]

21. Morcous, G.; Rivard, H.; Hanna, A. Case-Based Reasoning System for Modeling Infrastructure Deterioration. J. Comput. Civ. Eng. 2002, 16, 104-114. [CrossRef]

22. Hua Huang, Y. Artificial Neural Network Model of Bridge Deterioration. J. Perform. Constr. Facil. 2010, 24, 98-107. [CrossRef]

23. OECD. ITF Transport Outlook; OECD Library: Paris, France, 2019; ISBN 9789282150146. [CrossRef]

24. Calvi, G.M.; Moratti, M.; O’Reilly, G.J.; Scattarreggia, N.; Monteir, R.; Malomo, D.; Calvi, P.M.; Pinho, R. Once upon a Time in Italy: The Tale of the Morandi Bridge. Struct. Eng. Int. 2019, 29, 198-217. [CrossRef]

25. Zordan, T. From the Morandi Bridge to the Namawukulu Footbridge: A Clear Message of Commitment from IABSE. Struct. Eng. Int. 2018, 28, 393. [CrossRef]

26. Zhang, X.; Gao, H. Determining an Optimal Maintenance Period for Infrastructure Systems. Comput. Aided Civ. Infrastruct. Eng. 2012, 27, 543-554. [CrossRef]

27. Miyamoto, A.; Kawamura, K.; Nakamura, H. Bridge Management System and Maintenance Optimization for Existing Bridges. Comput. Aided Civ. Infrastruct. Eng. 2000, 15, 45-55. [CrossRef]

28. Elbehairy, H.; Elbeltagi, E.; Hegazy, T.; Soudki, K. Comparison of Two Evolutionary Algorithms for Optimization of Bridge Deck Repairs. Comput. Aided Civ. Infrastruct. Eng. 2006, 21, 561-572. [CrossRef]

29. Harmonising European ITS Services-Traffic Management Services. Dynamic Lane Management; DG05EU; Deployment Guideline; Trans-European Transport Network (TEN-T): Brussels, Belgium, 2015.

30. Blundell, F. Improvement Optimization Model, Posted in the On-line Pontis Technical Notes; JSTOR: New York, NY, USA, 1997.

31. Kleywegt, A.J.; Sinha, K.C. Tools for bridge management data analysis. Transp. Res. Circ. 1994, 423, 16-26.

32. Johnston, D.W.; Chen, C.; Abed-Al-Rahim, I. Developing user costs for bridge management systems. Transp. Res. Circ. 1994, $423,16$.

33. Son, Y.; Sinha, K. Methodology to estimate user costs in Indiana bridge management system. Transp. Res. Rec. 1997, 1597, 43-51. [CrossRef]

34. Fossetti, M.; Macaluso, G.; Siciliano, A.F.; Basone, F.; D’Arenzo, G. An innovative procedure to mechanical characterization of repairing materials under vehicle-induced vibrations. Structures 2020, 25, 943-955. [CrossRef] 
35. Brühwiler, E. Rehabilitation and strengthening of concrete structures using ultra-high performance fibre reinforced concrete. In Proceedings of the 3rd International Conference on Concrete Repair, Rehabilitation and Retrofitting, ICCRRR-3, Cape Town, South Africa, 3-5 September 2012; p. 30.

36. Testing Hardened Concrete. Compressive Strength of Test Specimens; EN 12390/3; CEN, Milam: Brussels, Belgium, 2003.

37. Test Method for Metallic Fibre Concrete-Measuring the Flexural Tensile Strength; EN 14651; Milam, UNI Milan: Brussels, Belgium, 2007.

38. Testing Hardened Concrete, Density of Hardened Concrete; EN 12390-7; Milam, UNI Milan: Brussels, Belgium, 2002.

39. Testing Concrete Part 4: Determination of ultrasonic Pulse Velocity; EN 12504-4; Milam, UNI Milan: Brussels, Belgium, 2005.

40. Fossetti, M.; Lo Iacono, F.; Minafò, G.; Navarra, G.; Tesoriere, G. A new large scale laboratory: The LEDA Research Centre (Laboratory of Earthquake engineering and Dynamic Analysis). In Proceedings of the International Conference on Advances in Experimental Structural Engineering Foundation EU Centre, Pavia, Italy, 18 September 2017; pp. 699-717, ISBN 978-888570102-1. [CrossRef]

41. Castellaro, S.; Barrasso, P.; Isani, S. Validazione del modello MIDAS di un viadotto per mezzo di caratterizzazione dinamica speditiva effettuata con Tromino. Struct. Model. CSPFEA 2016, 13, 26-33.

42. Castellaro, S. Soil and structure damping from single station measurements. Soil Dyn. Earthq. Eng. 2016, 90, 480-493. [CrossRef]

43. Praticò, F.G.; Giunta, M. Quantifying the effect of present, past and oncoming alignment on the operating speeds of a two-lane rural road. Balt. J. Road Bridge Eng. 2012, 7, 181-190. [CrossRef]

44. Methods of Testing Cement-Part 3: Determination of Setting Times and Soundness; EN 196-3; Milam, CEN: Brussels, Belgium, 2005.

45. Recommendation, RILEM Draft. Determination of the fracture energy of mortar and concrete by means of three-point bend tests on notched beams, International Union of Laboratories and Experts in Construction Materials. Syst. Struct. 1985, 18, 287-290.

46. Nguyen, H.; Carvelli, V.; Adesanya, E.; Kinnunen, P.; Illikainen, M. High performance cementitious composite from alkaliactivated ladle slag reinforced with polypropylene fibers. Cem. Concr. Compos. 2018, 90, 150-160. [CrossRef]

47. Karihaloo, B.L.; Nallathambi, P. Effective crack model for the determination of fracture toughness (Kelc) of concrete. Eng. Fract. Mech. 1990, 35, 637-645. [CrossRef]

48. Baraković, S.; Kasapović, S.; Baraković, J. Comparison of MANET Routing Protocols in Different Traffic and Mobility Models. Telfor J. 2010, 2, 1.

49. Psaraftis, H.N.; Wen, M.; Kontovas, C.A. Dynamic vehicle routing problems: Three decades and counting. Networks 2016, 67, 3-31. [CrossRef]

50. The Manual for Bridge Evaluation-U.S. Department of Transportation; Federal Highway Administration: Washington, DC, USA, 2018.

51. Bennetts, J.; Vardanega, P.J.; Taylor, C.A.; Denton, S.R. Survey of the use of data in UK bridge asset management. Proc. Inst. Civ. Eng. Bridge Eng. 2020, 173, 211-222. [CrossRef] 